Article

\title{
Antibacterial Activity of Honey Samples from Ukraine
}

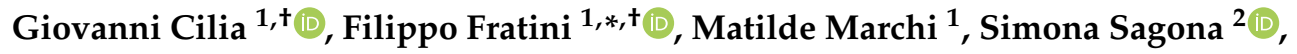 \\ Barbara Turchi ${ }^{1}$, Leonora Adamchuk ${ }^{3}$ (D) , Antonio Felicioli ${ }^{1}$ (D) and Miroslava Kačániová ${ }^{4,5}$ (D) \\ 1 Department of Veterinary Sciences, University of Pisa, Viale delle Piagge 2, 20159 Pisa, Italy; \\ giovanni.cilia@vet.unipi.it (G.C.); matildemarchi23@hotmail.it (M.M.); barbara.turchi@unipi.it (B.T.); \\ antonio.felicioli@unipi.it (A.F.) \\ 2 Department of Pharmacy, University of Pisa, via Bonanno 6, 56126 Pisa, Italy; simona.sagona@unipi.it \\ 3 Department of Horse-Breeding and Beekeeping, National University of Life and Environmental Sciences of \\ Ukraine, Henerala Rodimtseva Str.19, 03041 Kyiv, Ukraine; leonora.adamchuk@gmail.com \\ 4 Department of Fruit Sciences, Viticulture and Enology, Slovak University of Agriculture in Nitra, Tr. A. \\ Hlinku 2, 94976 Nitra, Slovakia; kacaniova.miroslava@gmail.com \\ 5 Department of Bioenergetics, Food Analysis and Microbiology, Institute of Food Technology and Nutrition, \\ University of Rzeszow, Cwiklinskiej 1, 35-601 Rzeszow, Poland \\ * Correspondence: filippo.fratini@unipi.it \\ + These authors equally contributed to this work.
}

Received: 2 November 2020; Accepted: 17 November 2020; Published: 20 November 2020

\begin{abstract}
The employment of natural substances such as beehive products with a preventive and therapeutic purpose has been a widespread custom since ancient times. In this investigation, the antibacterial activity of 41 honey samples from different Ukraine regions has been evaluated. For each honey, melissopalynological and physico-chemical analysis were performed in order to determine botanical origin, $\mathrm{pH}$, glucose and fructose contents and free acidity. So, antibacterial activity against Staphylococcus aureus CCM 4223, Listeria monocytogenes ATCC 7644, Salmonella enterica serovar Typhimurium CCM 3807 and Escherichia coli ATCC 25922 was assessed through the determination of MIC (Minimum Inhibitory Concentration) and MBC (Minimum Bactericidal Concentration) values by the microdilutions method. The results show that the most susceptible bacterial strain was $\mathrm{L}$. monocytogenes. Its growth was inhibited at a honey concentration ranging from 0.094 to $0.188 \mathrm{~g} / \mathrm{mL}$. The most resistant bacterial strain was S. aureus. As concerns MBC values, L. monocytogenes was the most susceptible bacteria, while $S$. aureus was the most resistant. Helianthus spp. honeys was the most effective against all tested bacterial strains, followed by Robinia spp. and multifloral honeys. Promising results for MIC tests have been found for Brassica spp.
\end{abstract}

Keywords: antibacterial activity; honey; minimal inhibitory concentration; minimal bactericidal concentration; melissopalynological analysis; physic-chemicals analysis

\section{Introduction}

Honey is an ancient remedy for treatment of infected wounds, which was recently "rediscovered" by the scientific community [1]. The first written reference to honey, a Sumerian tablet writing, dating back to 2100-2000 BC, mentions the use of honey as a drug and an ointment. Aristotle (384-322 BC) referred to pale honey as being "good as a salve for sore eyes and wounds". In most ancient cultures, honey was used for both nutritional and medical purposes. The belief that honey is a nutrient, a drug and an ointment still survives today, and thus an alternative medicine branch, has been developed in recent years, offering treatments against many diseases including bacterial infections based on honey and other bee products [1]. 
The antimicrobial activity of honey is highly complex and still not fully recognized. To date, it has been established that several honey components play a crucial role for its antimicrobial properties [2]. Furthermore, royal jelly, beeswax and bee venom highlighted antimicrobial activity against a wide range of bacteria [3-6]. The antimicrobial activity of honey is due to physicochemical properties, such as the high content of reducing sugars, high viscosity, high osmotic pressure, low $\mathrm{pH}$, low water activity (AW), low protein content and the presence of hydrogen peroxide [7,8]. None of these factors, taken individually, seem to be enough to explain the antimicrobial activity of honey, even if hydrogen peroxide and the bee-derived peptides with antibacterial activity were considered the major factors responsible for honey's antibacterial activity [9-11]. Indeed, antibacterial activity seems to be strictly connected to the botanical origin of the plant, highlighting that the plant-derived component, especially hydrogen peroxide and polyphenols, are strictly involved in the antibacterial action [9-11]. As for other natural antimicrobials, such as essential oils and hydrolates, the antimicrobial activity of honey seems to derive from many factors, partially characterized. An important role among these factors is played by osmolarity, which was the main reason for honey being used over time as a sweetener ingredient, and also in long-term food preparations, for example, in Mediterranean pastries [12]. In honey, $95-99 \%$ of the dry matter is made of sugars, particularly fructose and glucose. The amount of water present in the product is a critical factor for the stability and safety of the product. For this reason, this microorganism group represents the main limit for the extension of the shelf-life of honey, considering that the minimum AW for the development of osmophilic yeasts is 0.61-0.62 [13]. A great number of studies have shown that honey has a broad-spectrum antibacterial activity against Gram-positive and Gram-negative bacteria. Honey antibacterial activity against S. aureus, E. coli, and Salmonella sp. could vary on the basis of two honey sample features: floral origin diversity and countries of origin [14-19]. It has been shown that honeys with low levels of phenol and tocopherol have the highest antibacterial activity against clinical isolates of S. aureus, Proteus mirabilis, E. coli, and Shigella dysenteriae [20].

Given the importance in a study that honeys might exert antimicrobial activity against pathogenic bacteria in a relationship with the botanical origins, the aim of this investigation was to evaluate the antimicrobial activity of 41 honey samples from different Ukraine regions against two Gram-positive bacterial strains (S. aureus CCM 4223 and L. monocytogenes ATCC 7644) and two Gram-negative bacterial strains (Sal. enterica servovar Typhimurium CCM 3807 and E. coli ATCC 25922).

\section{Materials and Methods}

\subsection{Samples Collection}

Forty-one pure crude honey samples were obtained directly from beekeepers from different regions of Ukraine. All samples were collected by the Department of Horse-Breeding and Beekeeping in Kyiv. All honey samples were stored in sterile plastic flasks at room temperature in the dark.

In all honey samples, the absence of antibiotics is regulated by legislation (Ukraine SCBM Orden n. 143, 23/12/2004, Ukraine SCVM Order n. 40, 28/05/2003). Beekeepers demonstrated that the honey collected during the year of this investigation was tested to the presence of antibiotic residues in the honey. The analysis, carried out by external laboratories through HPLC, reported the absence of tetracyclines, sulphonamides and streptomycin in all honeys.

\subsection{Melissopalynological Analysis and Physico-Chemical Analysis}

The botanical origin of the samples of honey was based on the pollen spectrum, thought melissopalynological analysis [21]. The microscopic analysis of each honey for the palynological components identification were carried out according to the melissopalynological method. Briefly, $10 \mathrm{~g}$ of honey was mixed with $50 \mathrm{~mL}$ of distilled water and was centrifuged for $10 \mathrm{~min}$ at $3000 \mathrm{rpm}$. Afterwards, the precipitate was suspended again in distilled water and centrifuged for $7 \mathrm{~min}$ at $3000 \mathrm{rpm}$. The final precipitate was transferred in a microscope slide, dried and fixed using glycerin 
jelly for permanent preparations. Pollen grain identification was performed by optical microscope with total magnification $(400 \times$ and $1000 \times$ ) using as a reference a pollen collection from the Department of Horse-Breeding and Beekeeping in Kyiv and different pollen morphology guides. Only in order to characterize the tested honey samples, physico-chemical parameters were analyzed according the Official Methods of Analysis of Association of Official Analytical Chemists [22] and the Harmonised Methods of the European Honey Commission [23]. All honey samples were analyzed during the same time period to uniform the conditions and then comparability.

To $\mathrm{pH}$ measurement, $5 \mathrm{~g}$ of honey samples was diluted with $20 \mathrm{~mL}$ of distilled water and mixed thoroughly [22]. The $\mathrm{pH}$ was measured using the Digital pH Meter (pH-526 WTW Germany).

Free acidity was determined dissolving $10 \mathrm{~g}$ of honey samples in $75 \mathrm{~mL}$ of CO2-free water [22]. The electrode of the $\mathrm{pH}$ meter was immersed in the solution, stirred with a magnetic stirrer, and titrated to $\mathrm{pH} 8.5$ by adding $0.05 \mathrm{~N} \mathrm{NaOH}$ solution.

Glucose and fructose content were identified using a High-Pressure Liquid Chromatograph (HPLC), composed by Alliance Separations Module (Waters), Aminex HPX-87H $300 \times 7.8$ mm column, Cation-H precolumn and Refractive Index Detector (Waters). To measure sugars, $0.4 \mathrm{~g}$ of honey sample was dissolved in $3 \mathrm{~m}$ of milli-Q water and transferred volumetric flask. The solution was well mixed, and it was filtered through a $0.2 \mu \mathrm{m}$ Millipore filter and an additional 10× dilution was made with HPLC eluent.

\subsection{Bacterial Strains}

Four bacterial strains obtained from international type culture collections were tested: S. aureus CCM 4223, L. monocytogenes ATCC 7644, Sal. enterica serovar. Typhimurium CCM 3807 and E. coli ATTC 25922.

Strains were stored at $-80{ }^{\circ} \mathrm{C}$ in a glycerol suspension until their use. Before the antibacterial activity determinations, the strains were cultured in BHI (Brain Hearth Infusion, Oxoid, Milan, Italy) broth for $24 \mathrm{~h}$ at $37^{\circ} \mathrm{C}$ in aerobic conditions.

\subsection{Minimal Inhibitory Concentration (MIC) and Minimal Bactericidal Concentration (MBC)}

Honey samples were weighed $(1.5 \mathrm{~g})$ and diluted in $2 \mathrm{~mL}$ of BHI broth. In order to determine the MIC values, a microdilutions method was employed, using 96 -well polypropylene microtiter plates. In the first empty row of wells, $190 \mu \mathrm{L}$ of stock solution with honey and BHI was distributed, then twofold dilutions were performed. A total of $10 \mu \mathrm{L}$ of bacterial suspension was added to each well to reach a final volume of $200 \mu \mathrm{L}$ [24].

Bacterial suspensions were adjusted using the McFarland standard turbidity scale in order to obtain approximately $1.5 \times 10^{8} \mathrm{cfu} / \mathrm{mL}$ for each strain. As a negative control, sterile BHI broth was used. Microplates were incubated at $37^{\circ} \mathrm{C}$ for $24 \mathrm{~h}$ in a humid chamber in aerobic conditions.

$\mathrm{MBC}$ was determined by streaking one drop from each well that showed a concentration of honey equal to or higher than the MIC value on TSA (Trypticase Soy Agar) to evaluate microbial growth. TSA plates were incubated at $37^{\circ} \mathrm{C}$ for $24 \mathrm{~h}$. MBC values were determined as the lowest concentrations that did not allow colonies to grow.

\subsection{Statistical Analysis}

The MIC and MBC results were expressed as mode (the value that appears most often) and the comparison of the antibacterial activity of the samples was evaluated by applying $t$-test. $p \leq 0.05$ values were considered to indicate statistically significant differences. 


\section{Results}

\subsection{Melissopalynological and Physico-Chemical Analysis}

Honey botanical origins through melissopalynological analysis and $\mathrm{pH}$, glucose, fructose and free acidity are reported in Table 1 in relation with the provenience region. The sampled honeys were divided as follows: 11 samples of Helianthus honey, 10 of Robinia honey, 3 of Brassica honey, 2 of Tilia honey, 1 of Coriandrum sativum honey, 1 of Echium vulgare honey, 8 of multiflower honey, 3 of organic multiflower honey and 2 of multiflower honey from a medicinal plant.

Table 1. Characteristic of honey samples tested.

\begin{tabular}{|c|c|c|c|c|c|c|c|}
\hline \multirow{2}{*}{ Sample } & \multirow{2}{*}{ Botanical Origin } & \multirow{2}{*}{ Melissopalynology } & \multirow{2}{*}{ Provenience } & \multicolumn{4}{|c|}{ Physico-Chemical Analyses } \\
\hline & & & & $\mathrm{pH}$ & Glucose $^{1}$ & Fructose $^{1}$ & Acidity $^{2}$ \\
\hline 1 & Brassica spp. & $\begin{array}{c}\text { Brassica } 99 \% \\
\text { Taraxacum 1\% }\end{array}$ & Zhytomyr region & 4.2 & 47.5 & 42.3 & 14.8 \\
\hline 2 & $\begin{array}{l}\text { Multifloral (organic } \\
\text { honey) }\end{array}$ & $\begin{array}{c}\text { Medicago } 14 \% \\
\text { Helianthus } 12 \% \\
\text { Phacelia } 11 \% \\
\text { Tilia } 8 \%\end{array}$ & $\begin{array}{l}\text { Ivano-Frankivsk } \\
\text { region }\end{array}$ & 3.8 & 27.9 & 39.9 & 19.7 \\
\hline 3 & $\begin{array}{c}\text { Multifloral } \\
\text { (medicinal plants) }\end{array}$ & $\begin{array}{c}\text { Eucalyptus } 21 \% \\
\text { Phacelia } 12 \% \\
\text { Lavandula } 8 \% \\
\text { Thymus } 5 \%\end{array}$ & Kiev region & 3.9 & 25.5 & 37.4 & 30.4 \\
\hline 4 & Multifloral & $\begin{array}{c}\text { Castanea } 15 \% \\
\text { Tilia } 11 \% \\
\text { Thymus } 8 \% \\
\text { Phacelia } 2 \%\end{array}$ & Zhytomyr region & 3.8 & 28.9 & 42.5 & 33.0 \\
\hline 5 & Echium vulgare & $\begin{array}{c}\text { Echium } 61 \% \\
\text { Robinia } 12 \% \\
\text { Phacelia } 12 \% \\
\text { Thymus } 9 \%\end{array}$ & Kherson region & 3.8 & 30.1 & 41.9 & 28.0 \\
\hline 6 & Brassica spp. & $\begin{array}{c}\text { Brassica } 97 \% \\
\text { Taraxacum 3\% }\end{array}$ & Zhytomyr region & 3.8 & 47.1 & 44.7 & 10.7 \\
\hline 7 & $\begin{array}{l}\text { Multifloral (organic } \\
\text { honey) }\end{array}$ & $\begin{array}{c}\text { Eucalyptus } 18 \% \\
\text { Phacelia } 7 \% \\
\text { Thymus } 3 \%\end{array}$ & $\begin{array}{l}\text { Ivano-Frankivsk } \\
\text { region }\end{array}$ & 3.9 & 29.0 & 37.3 & 22.2 \\
\hline 8 & Helianthus spp. & $\begin{array}{c}\text { Helianthus } 69 \% \\
\text { Trifolium } 12 \% \\
\text { Tilia } 10 \% \\
\text { Medicago } 9 \%\end{array}$ & Kharkiv region & 3.8 & 37.0 & 42.8 & 24.7 \\
\hline 9 & Multifloral & $\begin{array}{l}\text { Rosmarinus } 20 \% \\
\text { Taraxacum } 10 \% \\
\text { Brassica } 8 \%\end{array}$ & Kiev region & 3.7 & 29.4 & 37.7 & 23.9 \\
\hline 10 & Robinia spp. & $\begin{array}{c}\text { Robinia } 25 \% \\
\text { Phacelia } 12 \% \\
\text { Taraxacum } 3 \%\end{array}$ & $\begin{array}{l}\text { Ukraine, industrial } \\
\text { honey }\end{array}$ & 3.9 & 26.1 & 41.3 & 11.3 \\
\hline 11 & Multifloral & $\begin{array}{c}\text { Eucalyptus } 21 \% \\
\text { Castanea } 13 \% \\
\text { Phacelia } 11 \% \\
\text { Trifolium } 5 \%\end{array}$ & Kiev region & 3.8 & 27.0 & 37.6 & 27.1 \\
\hline 12 & $\begin{array}{l}\text { Multifloral (organic } \\
\text { honey) }\end{array}$ & $\begin{array}{l}\text { Castanea } 17 \% \\
\text { Aesculus } 12 \% \\
\text { Phacelia } 11 \% \\
\text { Trifolium } 8 \% \\
\text { Thymus } 5 \%\end{array}$ & $\begin{array}{l}\text { Ivano-Frankivsk } \\
\text { region }\end{array}$ & 3.9 & 27.0 & 37.5 & 16.0 \\
\hline 13 & Helianthus spp. & $\begin{array}{l}\text { Helianthus } 71 \% \\
\text { Trifolium } 11 \% \\
\text { Medicago } 8 \%\end{array}$ & Zhytomyr region & 3.9 & 37.5 & 43.9 & 28.6 \\
\hline 14 & Robinia spp. & $\begin{array}{l}\text { Robinia 31\% } \\
\text { Castanea 11\% } \\
\text { Taraxacum } 4 \%\end{array}$ & $\begin{array}{l}\text { Ukraine, industrial } \\
\text { honey }\end{array}$ & 3.8 & 26.4 & 43.2 & 11.3 \\
\hline 15 & Robinia spp. & $\begin{array}{l}\text { Robinia } 27 \% \\
\text { Phacelia } 10 \% \\
\text { Castanea } 4 \%\end{array}$ & Kiev region & 3.5 & 27.1 & 42.4 & 11.6 \\
\hline 16 & Helianthus spp. & $\begin{array}{l}\text { Helianthus } 68 \% \\
\text { Medicago } 18 \% \\
\text { Trifolium } 14 \%\end{array}$ & Zhytomyr region & 3.9 & 36.9 & 43.4 & 21.0 \\
\hline 17 & Robinia spp. & $\begin{array}{l}\text { Robinia } 29 \% \\
\text { Phacelia } 11 \% \\
\text { Taraxacum } 6 \%\end{array}$ & $\begin{array}{l}\text { Ukraine, industrial } \\
\text { honey }\end{array}$ & 4.0 & 28.2 & 41.2 & 11.5 \\
\hline
\end{tabular}


Table 1. Cont.

\begin{tabular}{|c|c|c|c|c|c|c|c|}
\hline \multirow{2}{*}{ Sample } & \multirow{2}{*}{ Botanical Origin } & \multirow{2}{*}{ Melissopalynology } & \multirow{2}{*}{ Provenience } & \multicolumn{4}{|c|}{ Physico-Chemical Analyses } \\
\hline & & & & $\mathrm{pH}$ & Glucose $^{1}$ & Fructose $^{1}$ & Acidity $^{2}$ \\
\hline 18 & Helianthus spp. & $\begin{array}{c}\text { Helianthus } 80 \% \\
\text { Medicago } 11 \% \\
\text { Trifolium } 9 \%\end{array}$ & Kharkiv region & 3.9 & 37.0 & 42.5 & 27.9 \\
\hline 19 & Multifloral & $\begin{array}{l}\text { Rosmarinus } 17 \% \\
\text { Taraxacum } 12 \% \\
\text { Brassica } 7 \%\end{array}$ & Zhytomyr region & 3.8 & 32.5 & 40.7 & 34.6 \\
\hline 20 & Helianthus spp. & $\begin{array}{l}\text { Helianthus } 72 \% \\
\text { Medicago } 12 \% \\
\text { Trifolium } 10 \% \\
\text { Phacelia } 6 \%\end{array}$ & Kharkiv region & 3.8 & 37.5 & 44.6 & 28.6 \\
\hline 21 & Robinia spp. & $\begin{array}{c}\text { Robinia 35\% } \\
\text { Phacelia 9\% } \\
\text { Taraxacum 6\% }\end{array}$ & Donetsk region & 3.8 & 26.4 & 43.2 & 11.3 \\
\hline 22 & Multifloral & $\begin{array}{c}\text { Eucalyptus } 18 \% \\
\text { Phacelia } 13 \% \\
\text { Castanea } 9 \% \\
\text { Thymus } 3 \%\end{array}$ & Donetsk region & 3.8 & 31.4 & 37.4 & 18.1 \\
\hline 23 & Helianthus spp. & $\begin{array}{l}\text { Helianthus } 90 \% \\
\text { Medicago } 7 \% \\
\text { Trifolium } 3 \%\end{array}$ & Donetsk region & 3.9 & 37.6 & 43.1 & 24.2 \\
\hline 24 & Brassica spp. & $\begin{array}{c}\text { Brassica } 98 \% \\
\text { Taraxacum } 2 \%\end{array}$ & Kiev region & 4.1 & 49.3 & 42.4 & 13.3 \\
\hline 25 & Robinia spp. & $\begin{array}{l}\text { Robinia } 21 \% \\
\text { Phacelia } 10 \% \\
\text { Castanea } 8 \%\end{array}$ & $\begin{array}{l}\text { Ukraine, industrial } \\
\text { honey }\end{array}$ & 3.9 & 25.6 & 45.0 & 10.8 \\
\hline 26 & Robinia spp. & $\begin{array}{c}\text { Robinia } 34 \% \\
\text { Castanea } 13 \% \\
\text { Phacelia } 11 \% \\
\text { Taraxacum } 5 \%\end{array}$ & $\begin{array}{l}\text { Ukraine, industrial } \\
\text { honey }\end{array}$ & 4.0 & 26.9 & 44.1 & 11.3 \\
\hline 27 & Robinia spp. & $\begin{array}{l}\text { Robinia } 25 \% \\
\text { Castanea } 9 \% \\
\text { Taraxacum } 2 \%\end{array}$ & $\begin{array}{l}\text { Ukraine, industrial } \\
\text { honey }\end{array}$ & 4.0 & 26.2 & 43.5 & 10.9 \\
\hline 28 & Multifloral & $\begin{array}{c}\text { Castanea } 17 \% \\
\text { Aesculus } 12 \% \\
\text { Trifolium } 11 \% \\
\text { Thymus } 8 \% \\
\text { Lavandula } 5 \%\end{array}$ & Zhytomyr region & 3.9 & 31.9 & 37.9 & 20.8 \\
\hline 29 & Tilia spp. & $\begin{array}{c}\text { Tilia } 25 \% \\
\text { Castanea } 12 \%\end{array}$ & Kiev region & 4.5 & 28.5 & 41.6 & 24.3 \\
\hline 30 & Tilia spp. & $\begin{array}{c}\text { Tilia } 31 \% \\
\text { Castanea } 14 \%\end{array}$ & Kiev region & 4.2 & 30.1 & 41.9 & 19.8 \\
\hline 31 & $\begin{array}{c}\text { Multifloral } \\
\text { (medicinal plants) }\end{array}$ & $\begin{array}{c}\text { Eucalyptus } 23 \% \\
\text { Lavandula } 13 \% \\
\text { Phacelia } 9 \% \\
\text { Trifolium } 4 \%\end{array}$ & Kiev region & 3.9 & 31.8 & 38.7 & 26.2 \\
\hline 32 & Helianthus spp. & $\begin{array}{c}\text { Helianthus } 75 \% \\
\text { Medicago } 13 \% \\
\text { Trifolium } 12 \%\end{array}$ & Zhytomyr region & 3.8 & 38.2 & 44.8 & 20.3 \\
\hline 33 & Robinia spp. & $\begin{array}{l}\text { Robinia spp. } 39 \% \\
\text { Castanea } 12 \% \\
\text { Phacelia } 11 \%\end{array}$ & $\begin{array}{l}\text { Ukraine, industrial } \\
\text { honey }\end{array}$ & 3.7 & 26.0 & 45.7 & 10.1 \\
\hline 34 & Coriandrum sativum & $\begin{array}{l}\text { Coriandrum } 99 \% \\
\text { Castanea } 1 \%\end{array}$ & $\begin{array}{l}\text { Ukraine, industrial } \\
\text { honey }\end{array}$ & 3.9 & 35.7 & 35.9 & 30.0 \\
\hline 35 & Multifloral & $\begin{array}{c}\text { Taraxacum } 18 \% \\
\text { Brassica } 14 \% \\
\text { Rosmarinus } 3 \% \\
\text { Tilia } 2 \%\end{array}$ & Zhytomyr region & 3.9 & 25.3 & 39.4 & 18.2 \\
\hline 36 & Robinia spp. & $\begin{array}{c}\text { Robinia spp. } 28 \% \\
\text { Phacelia } 12 \% \\
\text { Castanea } 7 \% \\
\text { Taraxacum } 2 \%\end{array}$ & $\begin{array}{l}\text { Ukraine, industrial } \\
\text { honey }\end{array}$ & 4.0 & 26.2 & 42.5 & 8.7 \\
\hline 37 & Multifloral & $\begin{array}{c}\text { Eucalyptus } 17 \% \\
\text { Castanea } 16 \% \\
\text { Trifolium } 11 \% \\
\text { Thymus } 7 \%\end{array}$ & Zhytomyr region & 3.9 & 30.9 & 37.2 & 19.8 \\
\hline 38 & Helianthus spp. & $\begin{array}{l}\text { Helianthus } 81 \% \\
\text { Trifolium } 9 \% \\
\text { Medicago } 6 \%\end{array}$ & Zhytomyr region & 3.8 & 37.0 & 44.9 & 30.3 \\
\hline 39 & Helianthus spp. & $\begin{array}{l}\text { Helianthus } 99 \% \\
\text { Trifolium } 1 \%\end{array}$ & Zhytomyr region & 3.8 & 36.8 & 45.0 & 27.7 \\
\hline 40 & Helianthus spp. & $\begin{array}{l}\text { Helianthus } 91 \% \\
\text { Medicago } 9 \%\end{array}$ & Zhytomyr region & 3.9 & 36.9 & 43.8 & 24.6 \\
\hline 41 & Helianthus spp. & $\begin{array}{c}\text { Helianthus } 94 \% \\
\text { Trifolium } 6 \%\end{array}$ & Kharkiv region & 3.8 & 36.6 & 43.5 & 22.1 \\
\hline
\end{tabular}

Note. ${ }^{1}$ : expressed in $\mathrm{g} / 100 \mathrm{~g}$ of honey; ${ }^{2}$ : expressed in meq/kg of honey. 
Moreover, in accordance with the average values characteristic for each monofloral honey, the parameter of $\mathrm{pH}$, glucose, fructose and free acidity, evaluated in this investigation, are in accordance with the botanical origins of honey [22,23,25].

\subsection{Minimal Inhibitory Concentration and Minimal Bactericidal Concentration)}

The MIC and MBC values, reported in Table 2, showed that the most susceptible bacterial strain against the tested honey was L. monocytogenes, while E. coli and Sal. enterica were less susceptible. S. aureus was the most resistant bacterium. E. coli was the most susceptible to Helianthus spp. (samples 8 , 13, 16, 39 and 40), Robinia spp. (25 and 33), and multifloral (4, 7, 11, 12 and 35) honeys, which inhibited its growth at a concentration of $0.188 \mathrm{~g} / \mathrm{mL}$. Helianthus spp. honey (sample 14) is the only monofloral tested honey that inhibited Sal. enterica growth at a concentration of $0.094 \mathrm{~g} / \mathrm{mL}$. All the remaining honey samples inhibited Sal. enterica growth at a concentration of $0.188 \mathrm{~g} / \mathrm{mL}$ or $0.375 \mathrm{~g} / \mathrm{mL}$. The most resistant bacterial strain, $S$. aureus, has been inhibited only by two out of eleven Helianthus spp. honeys (samples 13 and 16) at a concentration of $0.094 \mathrm{~g} / \mathrm{mL}$ and by one out of three Brassica spp. honeys (sample 6) and one out of ten Robinia spp. honeys (sample 17) at a concentration of $0.188 \mathrm{~g} / \mathrm{mL}$. The other tested honeys inhibited its growth at a concentration of $0.375 \mathrm{~g} / \mathrm{mL}$. L. monocytogenes was the most susceptible bacterial strain to all tested honeys. All tested honeys inhibited L. monocytogenes growth at a concentration ranging from 0.094 to $0.375 \mathrm{~g} / \mathrm{mL}$.

Table 2. Results of Minimum Inhibitory Concentration (MIC) and Minimum Bactericidal Concentration (MBC) tests of honey (modal values).

\begin{tabular}{|c|c|c|c|c|}
\hline Honey Botanical Origin & Sample & Bacterial Strain & MIC Mode & MBC Mode \\
\hline \multirow{12}{*}{ Brassica spp. } & \multirow{4}{*}{1} & E. coli & $0.375 \mathrm{~g} / \mathrm{mL}$ & $>0.750 \mathrm{~g} / \mathrm{mL}$ \\
\hline & & Salmonella & $0.188 \mathrm{~g} / \mathrm{mL}$ & $>0.750 \mathrm{~g} / \mathrm{mL}$ \\
\hline & & L. monocytogenes & $0.188 \mathrm{~g} / \mathrm{mL}$ & $0.750 \mathrm{~g} / \mathrm{mL}$ \\
\hline & & S. aureus & $0.375 \mathrm{~g} / \mathrm{mL}$ & $>0.750 \mathrm{~g} / \mathrm{mL}$ \\
\hline & \multirow{4}{*}{6} & E. coli & $0.375 \mathrm{~g} / \mathrm{mL}$ & $0.750 \mathrm{~g} / \mathrm{mL}$ \\
\hline & & Salmonella & $0.375 \mathrm{~g} / \mathrm{mL}$ & $>0.750 \mathrm{~g} / \mathrm{mL}$ \\
\hline & & L. monocytogenes & $0.188 \mathrm{~g} / \mathrm{mL}$ & $>0.750 \mathrm{~g} / \mathrm{mL}$ \\
\hline & & S. aureus & $0.188 \mathrm{~g} / \mathrm{mL}$ & $>0.750 \mathrm{~g} / \mathrm{mL}$ \\
\hline & \multirow{4}{*}{24} & E. coli & $0.375 \mathrm{~g} / \mathrm{mL}$ & $0.375 \mathrm{~g} / \mathrm{mL}$ \\
\hline & & Salmonella & $0.188 \mathrm{~g} / \mathrm{mL}$ & $0.375 \mathrm{~g} / \mathrm{mL}$ \\
\hline & & L. monocytogenes & $0.188 \mathrm{~g} / \mathrm{mL}$ & $0.375 \mathrm{~g} / \mathrm{mL}$ \\
\hline & & S. aureus & $0.375 \mathrm{~g} / \mathrm{mL}$ & $>0.750 \mathrm{~g} / \mathrm{mL}$ \\
\hline \multirow{12}{*}{ Organic Multifloral } & \multirow{4}{*}{2} & E. coli & $0.375 \mathrm{~g} / \mathrm{mL}$ & $0.375 \mathrm{~g} / \mathrm{mL}$ \\
\hline & & Salmonella & $0.375 \mathrm{~g} / \mathrm{mL}$ & $0.750 \mathrm{~g} / \mathrm{mL}$ \\
\hline & & L. monocytogenes & $0.188 \mathrm{~g} / \mathrm{mL}$ & $0.188 \mathrm{~g} / \mathrm{mL}$ \\
\hline & & S. aureus & $0.375 \mathrm{~g} / \mathrm{mL}$ & $0.750 \mathrm{~g} / \mathrm{mL}$ \\
\hline & \multirow{4}{*}{7} & E. coli & $0.188 \mathrm{~g} / \mathrm{mL}$ & $0.750 \mathrm{~g} / \mathrm{mL}$ \\
\hline & & Salmonella & $0.188 \mathrm{~g} / \mathrm{mL}$ & $0.750 \mathrm{~g} / \mathrm{mL}$ \\
\hline & & L. monocytogenes & $0.094 \mathrm{~g} / \mathrm{mL}$ & $0.188 \mathrm{~g} / \mathrm{mL}$ \\
\hline & & S. aureus & $0.375 \mathrm{~g} / \mathrm{mL}$ & $0.375 \mathrm{~g} / \mathrm{mL}$ \\
\hline & \multirow{4}{*}{12} & E. coli & $0.188 \mathrm{~g} / \mathrm{mL}$ & $0.750 \mathrm{~g} / \mathrm{mL}$ \\
\hline & & Salmonella & $0.375 \mathrm{~g} / \mathrm{mL}$ & $0.375 \mathrm{~g} / \mathrm{mL}$ \\
\hline & & L. monocytogenes & $0.094 \mathrm{~g} / \mathrm{mL}$ & $0.188 \mathrm{~g} / \mathrm{mL}$ \\
\hline & & S. aureus & $0.375 \mathrm{~g} / \mathrm{mL}$ & $0.375 \mathrm{~g} / \mathrm{mL}$ \\
\hline \multirow{8}{*}{$\begin{array}{l}\text { Medicinal Plant } \\
\text { Multifloral }\end{array}$} & \multirow{4}{*}{3} & E. coli & $0.375 \mathrm{~g} / \mathrm{mL}$ & $>0.750 \mathrm{~g} / \mathrm{mL}$ \\
\hline & & Salmonella & $0.375 \mathrm{~g} / \mathrm{mL}$ & $>0.750 \mathrm{~g} / \mathrm{mL}$ \\
\hline & & L. monocytogenes & $0.375 \mathrm{~g} / \mathrm{mL}$ & $0.750 \mathrm{~g} / \mathrm{mL}$ \\
\hline & & S. aureus & $0.375 \mathrm{~g} / \mathrm{mL}$ & $>0.750 \mathrm{~g} / \mathrm{mL}$ \\
\hline & \multirow{4}{*}{31} & E. coli & $0.375 \mathrm{~g} / \mathrm{mL}$ & $0.750 \mathrm{~g} / \mathrm{mL}$ \\
\hline & & Salmonella & $0.375 \mathrm{~g} / \mathrm{mL}$ & $0.750 \mathrm{~g} / \mathrm{mL}$ \\
\hline & & L. monocytogenes & $0.375 \mathrm{~g} / \mathrm{mL}$ & $0.750 \mathrm{~g} / \mathrm{mL}$ \\
\hline & & S. aureus & $0.375 \mathrm{~g} / \mathrm{mL}$ & $0.750 \mathrm{~g} / \mathrm{mL}$ \\
\hline
\end{tabular}


Table 2. Cont.

\begin{tabular}{|c|c|c|c|c|}
\hline Honey Botanical Origin & Sample & Bacterial Strain & MIC Mode & MBC Mode \\
\hline \multirow{32}{*}{ Multifloral } & \multirow{4}{*}{4} & E. coli & $0.188 \mathrm{~g} / \mathrm{mL}$ & $0.188 \mathrm{~g} / \mathrm{mL}$ \\
\hline & & Salmonella & $0.188 \mathrm{~g} / \mathrm{mL}$ & $0.375 \mathrm{~g} / \mathrm{mL}$ \\
\hline & & L. monocytogenes & $0.375 \mathrm{~g} / \mathrm{mL}$ & $0.750 \mathrm{~g} / \mathrm{mL}$ \\
\hline & & S. aureus & $0.375 \mathrm{~g} / \mathrm{mL}$ & $0.750 \mathrm{~g} / \mathrm{mL}$ \\
\hline & \multirow{4}{*}{9} & E. coli & $0.375 \mathrm{~g} / \mathrm{mL}$ & $0.375 \mathrm{~g} / \mathrm{mL}$ \\
\hline & & Salmonella & $0.188 \mathrm{~g} / \mathrm{mL}$ & $0.375 \mathrm{~g} / \mathrm{mL}$ \\
\hline & & L. monocytogenes & $0.188 \mathrm{~g} / \mathrm{mL}$ & $0.188 \mathrm{~g} / \mathrm{mL}$ \\
\hline & & S. aureus & $0.375 \mathrm{~g} / \mathrm{mL}$ & $0.375 \mathrm{~g} / \mathrm{mL}$ \\
\hline & \multirow{4}{*}{11} & E. coli & $0.188 \mathrm{~g} / \mathrm{mL}$ & $0.375 \mathrm{~g} / \mathrm{mL}$ \\
\hline & & Salmonella & $0.188 \mathrm{~g} / \mathrm{mL}$ & $0.375 \mathrm{~g} / \mathrm{mL}$ \\
\hline & & L. monocytogenes & $0.188 \mathrm{~g} / \mathrm{mL}$ & $0.188 \mathrm{~g} / \mathrm{mL}$ \\
\hline & & S. aureus & $0.375 \mathrm{~g} / \mathrm{mL}$ & $>0.750 \mathrm{~g} / \mathrm{mL}$ \\
\hline & \multirow{4}{*}{19} & E. coli & $0.375 \mathrm{~g} / \mathrm{mL}$ & $0.750 \mathrm{~g} / \mathrm{mL}$ \\
\hline & & Salmonella & $0.375 \mathrm{~g} / \mathrm{mL}$ & $0.750 \mathrm{~g} / \mathrm{mL}$ \\
\hline & & L. monocytogenes & $0.188 \mathrm{~g} / \mathrm{mL}$ & $0.750 \mathrm{~g} / \mathrm{mL}$ \\
\hline & & S. aureus & $0.375 \mathrm{~g} / \mathrm{mL}$ & $0.375 \mathrm{~g} / \mathrm{mL}$ \\
\hline & \multirow{4}{*}{22} & E. coli & $0.375 \mathrm{~g} / \mathrm{mL}$ & $0.375 \mathrm{~g} / \mathrm{mL}$ \\
\hline & & Salmonella & $0.375 \mathrm{~g} / \mathrm{mL}$ & $0.750 \mathrm{~g} / \mathrm{mL}$ \\
\hline & & L. monocytogenes & $0.188 \mathrm{~g} / \mathrm{mL}$ & $0.375 \mathrm{~g} / \mathrm{mL}$ \\
\hline & & S. aureus & $0.375 \mathrm{~g} / \mathrm{mL}$ & $0.750 \mathrm{~g} / \mathrm{mL}$ \\
\hline & \multirow{4}{*}{28} & E. coli & $0.375 \mathrm{~g} / \mathrm{mL}$ & $0.375 \mathrm{~g} / \mathrm{mL}$ \\
\hline & & Salmonella & $0.375 \mathrm{~g} / \mathrm{mL}$ & $0.375 \mathrm{~g} / \mathrm{mL}$ \\
\hline & & L. monocytogenes & $0.188 \mathrm{~g} / \mathrm{mL}$ & $0.188 \mathrm{~g} / \mathrm{mL}$ \\
\hline & & S. aureus & $0.375 \mathrm{~g} / \mathrm{mL}$ & $0.375 \mathrm{~g} / \mathrm{mL}$ \\
\hline & \multirow{4}{*}{35} & E. coli & $0.188 \mathrm{~g} / \mathrm{mL}$ & $0.750 \mathrm{~g} / \mathrm{mL}$ \\
\hline & & Salmonella & $0.188 \mathrm{~g} / \mathrm{mL}$ & $0.750 \mathrm{~g} / \mathrm{mL}$ \\
\hline & & L. monocytogenes & $0.188 \mathrm{~g} / \mathrm{mL}$ & $0.188 \mathrm{~g} / \mathrm{mL}$ \\
\hline & & S. aureus & $0.375 \mathrm{~g} / \mathrm{mL}$ & $0.750 \mathrm{~g} / \mathrm{mL}$ \\
\hline & & E. coli & $0.375 \mathrm{~g} / \mathrm{mL}$ & $>0.750 \mathrm{~g} / \mathrm{mL}$ \\
\hline & & Salmonella & $0.375 \mathrm{~g} / \mathrm{mL}$ & $0.375 \mathrm{~g} / \mathrm{mL}$ \\
\hline & 37 & L. monocytogenes & $0.188 \mathrm{~g} / \mathrm{mL}$ & $0.750 \mathrm{~g} / \mathrm{mL}$ \\
\hline & & S. aureus & $0.375 \mathrm{~g} / \mathrm{mL}$ & $0.750 \mathrm{~g} / \mathrm{mL}$ \\
\hline \multirow{4}{*}{ E. vulgare } & \multirow{4}{*}{5} & E. coli & $0.375 \mathrm{~g} / \mathrm{mL}$ & $0.750 \mathrm{~g} / \mathrm{mL}$ \\
\hline & & Salmonella & $0.188 \mathrm{~g} / \mathrm{mL}$ & $0.375 \mathrm{~g} / \mathrm{mL}$ \\
\hline & & L. monocytogenes & $0.188 \mathrm{~g} / \mathrm{mL}$ & $0.375 \mathrm{~g} / \mathrm{mL}$ \\
\hline & & S. aureus & $0.375 \mathrm{~g} / \mathrm{mL}$ & $0.750 \mathrm{~g} / \mathrm{mL}$ \\
\hline \multirow{16}{*}{ Helianthus spp. } & \multirow{4}{*}{8} & E. coli & $0.188 \mathrm{~g} / \mathrm{mL}$ & $0.750 \mathrm{~g} / \mathrm{mL}$ \\
\hline & & Salmonella & $0.188 \mathrm{~g} / \mathrm{mL}$ & $>0.75 \mathrm{~g} / \mathrm{mL}$ \\
\hline & & L. monocytogenes & $0.375 \mathrm{~g} / \mathrm{mL}$ & $0.750 \mathrm{~g} / \mathrm{mL}$ \\
\hline & & S. aureus & $0.375 \mathrm{~g} / \mathrm{mL}$ & $>0.750 \mathrm{~g} / \mathrm{mL}$ \\
\hline & \multirow{4}{*}{13} & E. coli & $0.188 \mathrm{~g} / \mathrm{mL}$ & $0.375 \mathrm{~g} / \mathrm{mL}$ \\
\hline & & Salmonella & $0.094 \mathrm{~g} / \mathrm{mL}$ & $0.375 \mathrm{~g} / \mathrm{mL}$ \\
\hline & & L. monocytogenes & $0.094 \mathrm{~g} / \mathrm{mL}$ & $0.188 \mathrm{~g} / \mathrm{mL}$ \\
\hline & & S. aureus & $0.094 \mathrm{~g} / \mathrm{mL}$ & $0.188 \mathrm{~g} / \mathrm{mL}$ \\
\hline & \multirow{4}{*}{16} & E. coli & $0.188 \mathrm{~g} / \mathrm{mL}$ & $0.188 \mathrm{~g} / \mathrm{mL}$ \\
\hline & & Salmonella & $0.188 \mathrm{~g} / \mathrm{mL}$ & $0.188 \mathrm{~g} / \mathrm{mL}$ \\
\hline & & L. monocytogenes & $0.094 \mathrm{~g} / \mathrm{mL}$ & $0.188 \mathrm{~g} / \mathrm{mL}$ \\
\hline & & S. aureus & $0.094 \mathrm{~g} / \mathrm{mL}$ & $0.375 \mathrm{~g} / \mathrm{mL}$ \\
\hline & \multirow{4}{*}{18} & E. coli & $0.375 \mathrm{~g} / \mathrm{mL}$ & $0.750 \mathrm{~g} / \mathrm{mL}$ \\
\hline & & Salmonella & $0.375 \mathrm{~g} / \mathrm{mL}$ & $>0.750 \mathrm{~g} / \mathrm{mL}$ \\
\hline & & L. monocytogenes & $0.188 \mathrm{~g} / \mathrm{mL}$ & $0.750 \mathrm{~g} / \mathrm{mL}$ \\
\hline & & S. aureus & $0.375 \mathrm{~g} / \mathrm{mL}$ & $0.750 \mathrm{~g} / \mathrm{mL}$ \\
\hline
\end{tabular}


Table 2. Cont.

\begin{tabular}{|c|c|c|c|c|}
\hline Honey Botanical Origin & Sample & Bacterial Strain & MIC Mode & MBC Mode \\
\hline \multirow{28}{*}{ Helianthus spp. } & \multirow{4}{*}{20} & E. coli & $0.375 \mathrm{~g} / \mathrm{mL}$ & $0.750 \mathrm{~g} / \mathrm{mL}$ \\
\hline & & Salmonella & $0.375 \mathrm{~g} / \mathrm{mL}$ & $>0.750 \mathrm{~g} / \mathrm{mL}$ \\
\hline & & L. monocytogenes & $0.375 \mathrm{~g} / \mathrm{mL}$ & $0.750 \mathrm{~g} / \mathrm{mL}$ \\
\hline & & S. aureus & $0.375 \mathrm{~g} / \mathrm{mL}$ & $>0.750 \mathrm{~g} / \mathrm{mL}$ \\
\hline & \multirow{4}{*}{23} & E. coli & $0.375 \mathrm{~g} / \mathrm{mL}$ & $0.375 \mathrm{~g} / \mathrm{mL}$ \\
\hline & & Salmonella & $0.188 \mathrm{~g} / \mathrm{mL}$ & $0.375 \mathrm{~g} / \mathrm{mL}$ \\
\hline & & L. monocytogenes & $0.188 \mathrm{~g} / \mathrm{mL}$ & $0.188 \mathrm{~g} / \mathrm{mL}$ \\
\hline & & S. aureus & $0.375 \mathrm{~g} / \mathrm{mL}$ & $0.375 \mathrm{~g} / \mathrm{mL}$ \\
\hline & \multirow{4}{*}{32} & E. coli & $0.375 \mathrm{~g} / \mathrm{mL}$ & $0.750 \mathrm{~g} / \mathrm{mL}$ \\
\hline & & Salmonella & $0.375 \mathrm{~g} / \mathrm{mL}$ & $0.750 \mathrm{~g} / \mathrm{mL}$ \\
\hline & & L. monocytogenes & $0.188 \mathrm{~g} / \mathrm{mL}$ & $0.188 \mathrm{~g} / \mathrm{mL}$ \\
\hline & & S. aureus & $0.375 \mathrm{~g} / \mathrm{mL}$ & $0.750 \mathrm{~g} / \mathrm{mL}$ \\
\hline & \multirow{4}{*}{38} & E. coli & $0.375 \mathrm{~g} / \mathrm{mL}$ & $0.750 \mathrm{~g} / \mathrm{mL}$ \\
\hline & & Salmonella & $0.375 \mathrm{~g} / \mathrm{mL}$ & $>0.750 \mathrm{~g} / \mathrm{mL}$ \\
\hline & & L. monocytogenes & $0.188 \mathrm{~g} / \mathrm{mL}$ & $0.188 \mathrm{~g} / \mathrm{mL}$ \\
\hline & & S. aureus & $0.375 \mathrm{~g} / \mathrm{mL}$ & $0.750 \mathrm{~g} / \mathrm{mL}$ \\
\hline & \multirow{4}{*}{39} & E. coli & $0.188 \mathrm{~g} / \mathrm{mL}$ & $>0.75 \mathrm{~g} / \mathrm{mL}$ \\
\hline & & Salmonella & $0.188 \mathrm{~g} / \mathrm{mL}$ & $0.75 \mathrm{~g} / \mathrm{mL}$ \\
\hline & & L. monocytogenes & $0.188 \mathrm{~g} / \mathrm{mL}$ & $0.188 \mathrm{~g} / \mathrm{mL}$ \\
\hline & & S. aureus & $0.375 \mathrm{~g} / \mathrm{mL}$ & $0.375 \mathrm{~g} / \mathrm{mL}$ \\
\hline & \multirow{4}{*}{40} & E. coli & $0.188 \mathrm{~g} / \mathrm{mL}$ & $0.188 \mathrm{~g} / \mathrm{mL}$ \\
\hline & & Salmonella & $0.375 \mathrm{~g} / \mathrm{mL}$ & $0.75 \mathrm{~g} / \mathrm{mL}$ \\
\hline & & L. monocytogenes & $0.094 \mathrm{~g} / \mathrm{mL}$ & $0.188 \mathrm{~g} / \mathrm{mL}$ \\
\hline & & S. aureus & $0.375 \mathrm{~g} / \mathrm{mL}$ & $0.75 \mathrm{~g} / \mathrm{mL}$ \\
\hline & \multirow{4}{*}{41} & E. coli & $0.375 \mathrm{~g} / \mathrm{mL}$ & $0.75 \mathrm{~g} / \mathrm{mL}$ \\
\hline & & Salmonella & $0.375 \mathrm{~g} / \mathrm{mL}$ & $>0.75 \mathrm{~g} / \mathrm{mL}$ \\
\hline & & L. monocytogenes & $0.375 \mathrm{~g} / \mathrm{mL}$ & $0.375 \mathrm{~g} / \mathrm{mL}$ \\
\hline & & S. aureus & $0.375 \mathrm{~g} / \mathrm{mL}$ & $0.75 \mathrm{~g} / \mathrm{mL}$ \\
\hline \multirow{24}{*}{ Robinia spp. } & \multirow{4}{*}{10} & E. coli & $0.375 \mathrm{~g} / \mathrm{mL}$ & $0.750 \mathrm{~g} / \mathrm{mL}$ \\
\hline & & Salmonella & $0.375 \mathrm{~g} / \mathrm{mL}$ & $0.750 \mathrm{~g} / \mathrm{mL}$ \\
\hline & & L. monocytogenes & $0.375 \mathrm{~g} / \mathrm{mL}$ & $0.750 \mathrm{~g} / \mathrm{mL}$ \\
\hline & & S. aureus & $0.375 \mathrm{~g} / \mathrm{mL}$ & $>0.750 \mathrm{~g} / \mathrm{mL}$ \\
\hline & \multirow{4}{*}{14} & E. coli & $0.375 \mathrm{~g} / \mathrm{mL}$ & $>0.750 \mathrm{~g} / \mathrm{mL}$ \\
\hline & & Salmonella & $0.375 \mathrm{~g} / \mathrm{mL}$ & $>0.750 \mathrm{~g} / \mathrm{mL}$ \\
\hline & & L. monocytogenes & $0.375 \mathrm{~g} / \mathrm{mL}$ & $0.750 \mathrm{~g} / \mathrm{mL}$ \\
\hline & & S. aureus & $0.375 \mathrm{~g} / \mathrm{mL}$ & $0.750 \mathrm{~g} / \mathrm{mL}$ \\
\hline & \multirow{4}{*}{15} & E. coli & $0.375 \mathrm{~g} / \mathrm{mL}$ & $0.750 \mathrm{~g} / \mathrm{mL}$ \\
\hline & & Salmonella & $0.375 \mathrm{~g} / \mathrm{mL}$ & $>0.750 \mathrm{~g} / \mathrm{mL}$ \\
\hline & & L. monocytogenes & $0.375 \mathrm{~g} / \mathrm{mL}$ & $0.750 \mathrm{~g} / \mathrm{mL}$ \\
\hline & & S. aureus & $0.375 \mathrm{~g} / \mathrm{mL}$ & $0.750 \mathrm{~g} / \mathrm{mL}$ \\
\hline & \multirow{4}{*}{17} & E. coli & $0.375 \mathrm{~g} / \mathrm{mL}$ & $0.750 \mathrm{~g} / \mathrm{mL}$ \\
\hline & & Salmonella & $0.375 \mathrm{~g} / \mathrm{mL}$ & $0.750 \mathrm{~g} / \mathrm{mL}$ \\
\hline & & L. monocytogenes & $0.188 \mathrm{~g} / \mathrm{mL}$ & $0.375 \mathrm{~g} / \mathrm{mL}$ \\
\hline & & S. aureus & $0.188 \mathrm{~g} / \mathrm{mL}$ & $>0.750 \mathrm{~g} / \mathrm{mL}$ \\
\hline & \multirow{4}{*}{21} & E. coli & $0.375 \mathrm{~g} / \mathrm{mL}$ & $0.750 \mathrm{~g} / \mathrm{mL}$ \\
\hline & & Salmonella & $0.375 \mathrm{~g} / \mathrm{mL}$ & $>0.750 \mathrm{~g} / \mathrm{mL}$ \\
\hline & & L. monocytogenes & $0.375 \mathrm{~g} / \mathrm{mL}$ & $0.750 \mathrm{~g} / \mathrm{mL}$ \\
\hline & & S. aureus & $0.375 \mathrm{~g} / \mathrm{mL}$ & $>0.750 \mathrm{~g} / \mathrm{mL}$ \\
\hline & \multirow{4}{*}{25} & E. coli & $0.188 \mathrm{~g} / \mathrm{mL}$ & $0.750 \mathrm{~g} / \mathrm{mL}$ \\
\hline & & Salmonella & $0.188 \mathrm{~g} / \mathrm{mL}$ & $0.750 \mathrm{~g} / \mathrm{mL}$ \\
\hline & & L. monocytogenes & $0.188 \mathrm{~g} / \mathrm{mL}$ & $0.750 \mathrm{~g} / \mathrm{mL}$ \\
\hline & & S. aureus & $0.375 \mathrm{~g} / \mathrm{mL}$ & $>0.750 \mathrm{~g} / \mathrm{mL}$ \\
\hline
\end{tabular}


Table 2. Cont

\begin{tabular}{|c|c|c|c|c|}
\hline Honey Botanical Origin & Sample & Bacterial Strain & MIC Mode & MBC Mode \\
\hline \multirow{4}{*}{ Robinia spp. } & 26 & $\begin{array}{c}\text { E. coli } \\
\text { Salmonella } \\
\text { L. monocytogenes } \\
\text { S. aureus }\end{array}$ & $\begin{array}{l}0.375 \mathrm{~g} / \mathrm{mL} \\
0.375 \mathrm{~g} / \mathrm{mL} \\
0.375 \mathrm{~g} / \mathrm{mL} \\
0.375 \mathrm{~g} / \mathrm{mL}\end{array}$ & $\begin{array}{c}0.750 \mathrm{~g} / \mathrm{mL} \\
>0.750 \mathrm{~g} / \mathrm{mL} \\
0.750 \mathrm{~g} / \mathrm{mL} \\
>0.750 \mathrm{~g} / \mathrm{mL}\end{array}$ \\
\hline & 27 & $\begin{array}{c}\text { E. coli } \\
\text { Salmonella } \\
\text { L. monocytogenes } \\
\text { S. aureus }\end{array}$ & $\begin{array}{l}0.375 \mathrm{~g} / \mathrm{mL} \\
0.188 \mathrm{~g} / \mathrm{mL} \\
0.188 \mathrm{~g} / \mathrm{mL} \\
0.375 \mathrm{~g} / \mathrm{mL}\end{array}$ & $\begin{array}{c}>0.750 \mathrm{~g} / \mathrm{mL} \\
>0.750 \mathrm{~g} / \mathrm{mL} \\
0.750 \mathrm{~g} / \mathrm{mL} \\
>0.750 \mathrm{~g} / \mathrm{mL}\end{array}$ \\
\hline & 33 & $\begin{array}{c}\text { E. coli } \\
\text { Salmonella } \\
\text { L. monocytogenes } \\
\text { S. aureus }\end{array}$ & $\begin{array}{l}0.188 \mathrm{~g} / \mathrm{mL} \\
0.188 \mathrm{~g} / \mathrm{mL} \\
0.188 \mathrm{~g} / \mathrm{mL} \\
0.375 \mathrm{~g} / \mathrm{mL}\end{array}$ & $\begin{array}{c}0.750 \mathrm{~g} / \mathrm{mL} \\
>0.750 \mathrm{~g} / \mathrm{mL} \\
0.750 \mathrm{~g} / \mathrm{mL} \\
0.375 \mathrm{~g} / \mathrm{mL}\end{array}$ \\
\hline & 36 & $\begin{array}{c}\text { E. coli } \\
\text { Salmonella } \\
\text { L. monocytogenes } \\
\text { S. aureus }\end{array}$ & $\begin{array}{c}>0.750 \mathrm{~g} / \mathrm{mL} \\
>0.750 \mathrm{~g} / \mathrm{mL} \\
0.188 \mathrm{~g} / \mathrm{mL} \\
0.375 \mathrm{~g} / \mathrm{mL}\end{array}$ & $\begin{array}{c}>0.750 \mathrm{~g} / \mathrm{mL} \\
>0.750 \mathrm{~g} / \mathrm{mL} \\
0.750 \mathrm{~g} / \mathrm{mL} \\
0.750 \mathrm{~g} / \mathrm{mL}\end{array}$ \\
\hline \multirow{2}{*}{ Tilia spp. } & 29 & $\begin{array}{c}\text { E. coli } \\
\text { Salmonella } \\
\text { L. monocytogenes } \\
\text { S. aureus }\end{array}$ & $\begin{array}{l}0.375 \mathrm{~g} / \mathrm{mL} \\
0.188 \mathrm{~g} / \mathrm{mL} \\
0.188 \mathrm{~g} / \mathrm{mL} \\
0.375 \mathrm{~g} / \mathrm{mL}\end{array}$ & $\begin{array}{c}0.375 \mathrm{~g} / \mathrm{mL} \\
0.375 \mathrm{~g} / \mathrm{mL} \\
0.375 \mathrm{~g} / \mathrm{mL} \\
>0.750 \mathrm{~g} / \mathrm{mL}\end{array}$ \\
\hline & 30 & $\begin{array}{c}\text { E. coli } \\
\text { Salmonella } \\
\text { L. monocytogenes } \\
\text { S. aureus }\end{array}$ & $\begin{array}{l}0.375 \mathrm{~g} / \mathrm{mL} \\
0.188 \mathrm{~g} / \mathrm{mL} \\
0.375 \mathrm{~g} / \mathrm{mL} \\
0.375 \mathrm{~g} / \mathrm{mL}\end{array}$ & $\begin{array}{c}>0.750 \mathrm{~g} / \mathrm{mL} \\
0.750 \mathrm{~g} / \mathrm{mL} \\
>0.750 \mathrm{~g} / \mathrm{mL} \\
0.750 \mathrm{~g} / \mathrm{mL}\end{array}$ \\
\hline C. sativum & 34 & $\begin{array}{c}\text { E. coli } \\
\text { Salmonella } \\
\text { L. monocytogenes } \\
\text { S. aureus }\end{array}$ & $\begin{array}{l}0.375 \mathrm{~g} / \mathrm{mL} \\
0.188 \mathrm{~g} / \mathrm{mL} \\
0.375 \mathrm{~g} / \mathrm{mL} \\
0.375 \mathrm{~g} / \mathrm{mL}\end{array}$ & $\begin{array}{c}>0.750 \mathrm{~g} / \mathrm{mL} \\
0.750 \mathrm{~g} / \mathrm{mL} \\
0.750 \mathrm{~g} / \mathrm{mL} \\
>0.750 \mathrm{~g} / \mathrm{mL}\end{array}$ \\
\hline
\end{tabular}

Helianthus spp. honeys was the most effective against all tested bacterial strains, followed by Robinia spp. and multifloral honeys $(p=0.01)$. Only Sal. enterica and L. monocytogenes were inhibited at a concentration of $0.188 \mathrm{~g} / \mathrm{mL}$ by a wide range of tested monofloral and multifloral honeys, including E. vulgare and C. sativum. The most effective honey against all tested bacterial strains was Helianthus spp. honey $(p=0.02)$, followed by multifloral honeys, while the activity of Robinia spp. was moderate. Monofloral and multifloral honeys showed no differences among their antibacterial activity $(p=0.17)$. Thus, the antibacterial activity of multifloral honeys could be due to the same components present in monofloral honeys.

\section{Discussion}

The antibacterial activity of honey is strictly related to botanical source, the metabolism of honey bees, environmental-seasonal-climatic processing procedures and storage conditions, which have a strong influence on the physical and chemical property of this "medical" food, including antimicrobial properties [14-17,26-30]. Antimicrobial compounds of honey can be divided in two different groups: those with peroxide action and those with non-peroxide action. Hydrogen peroxide, especially derived from plants, is the component responsible for the antibacterial activity of honey compound with peroxide action $[26,31,32]$. It is produced under aerobic conditions by glucose oxidase from glucose [33]. Other factors are involved in the antimicrobial and antibacterial activity of honey: high osmolarity, acidity, antioxidant activity, nitric-oxide, limphocytic and phagocytic activity increase, and prostaglandins' reduction. These factors can inhibit bacterial growth and toxin production and affect bacterial biofilm expression, and bacterial cell wall structure [34]. 
The great antibacterial activity of Helianthus spp. honey could be related to the high value (compared to other honeys) of acidity (mean value 25.5). Free acidity has affected against bacteria in synergy with the $\mathrm{pH}$ action and sugars amount [29,35-37]. Fructose and sucrose, reported in high levels in Robinia spp. monofloral honey (mean value 43.2), could be involved in antibacterial activity. The high level of glucose (mean value 50.3) reported for Brassica honey and low level of glucose reported for Robinia spp. honey (mean value 26.5) indicate that this sugar could not play a role in antibacterial activity, or its activity is exclusively against specific bacteria, in this investigation S. aureus [37,38]. The antibacterial activity of honey was deeply investigated, both for monofloral and multifloral samples. According to these data, several bacteria are inhibited by honey, and in some cases are killed. Moreover, all tested honey evidenced higher values of MBC in comparison to MIC ones. These differences, usually common for many other antimicrobial substances derived from natural product $[6,24,39]$ have been also reported in other several researches on honey [11,40-42]. L. monocytogenes was one of the most susceptible among tested bacteria in accordance with other data available in literature [43-45]. Its growth was inhibited by the monofloral honey of Helianthus spp. [26,43-45] and Trifolium spp. [26] and by different multifloral honeys [43-45]. Robinia spp. and Tilia spp. monofloral honeys were less effective against L. monocytogenes [43-45]. The high susceptibility of L. monocytogenes to Robinia spp. and Tilia spp. monofloral honeys here reported seems to be related to the different strains employed or tests performed to evaluate MIC. In this investigation, the antibacterial activity of honeys against L. monocytogenes ATCC 7644 was assessed by the determination of MIC in a microdilution method, while, in the other studies, the agar-well diffusion method on L. monocytogenes ATCC 19115 was performed [43-45].

In this investigation, in accordance with other studies [43-45], Helianthus spp. honeys showed the highest antibacterial activity against E. coli, followed by Tilia and Robinia spp. Different honeys, in general, showed inhibitory activity against $E$. coli growth [26,41,46-49], but other authors found that multifloral honeys tested against $E$. coli showed a lack of significant susceptibility [50,51]. Robinia spp. honeys showed a good antibacterial activity against E. coli in accordance with Chang et al. (2011), but the Tilia honeys tested show a low activity. In the present investigation, detected MIC values concerning Tilia honey against E. coli are, instead, in accordance with Fidaleo et al. (2011) and Vica et al. (2014). It is possible to assume that the differences in the results can be related to the different bacterial strains employed. Indeed, E. coli ATCC 25922 used in this investigation is the same strain employed in two studies [45,52].

In this investigation, Sal. Enterica showed a wide spectrum of response with tested honeys, in accordance with other studies [26,47,53]. Monofloral Helianthus spp. honey inhibited different pathogens, among which is Sal. enterica [26]. Chestnut honeys and multifloral honeys from Sicily were tested against Sal. enterica serovar Infantis evidencing great antimicrobial activity [54].

In this investigation, the most resistant bacterial strain was S. aureus, for which the higher MIC and MBC values for all tested honeys have been reported, even if this bacterium is usually described as the most sensitive to honey's antimicrobial activity. Monofloral and multifloral honeys are able to inhibit S. aureus growth $[7,44,45,52,55]$. S. aureus was the most sensitive bacterial strain to Helianthus spp. and Tilia spp. monofloral honeys. Moreover, in literature, Robinia spp. and Brassica napus monofloral honeys, showed antibacterial activity against $S$. aureus $[45,56,57]$. On the other hand, several studies highlighted the high susceptibility of $S$. aureus, especially compared to Gram-negative bacteria $[9,11,34,58,59]$. These differences in the antibacterial activity could be related to the geographical provenience of honey, the environment of collection zone, the genetic of honeybee and its family could influence the properties of honey.

\section{Conclusions}

In conclusion, the different antibacterial activity of honey against the same bacterial strains tested in this investigation could be attributed to several factors, including provenience and physico-chemical properties (such as $\mathrm{pH}$, glucose and fructose content and free acidity). It could be possible that 
the different bacterial strains employed resulted in a different susceptibility degree within different antimicrobial activity evaluation tests. Moreover, the antibacterial activity could be related to different Robiania spp., Helianthus spp., Brassica spp. and Tilia spp. monofloral honeys' proveniences. The geographical provenience of honey, the surrounding environment of the collection zone, and the genetics of the honeybee and its family could influence the properties of honey and its antibacterial activity [60-63].

Moreover, the added antimicrobial peptides (AMPs) or antibacterial peptides, in different concentrations for each honeybee family, could play a role in the different antibacterial activity of honey. The physical-chemical features derived from plant compounds and honeybee factors change in each honey, as well as in honey derived from the same botanical source.

Author Contributions: Conceptualization, F.F., A.F. and M.K.; sampling, L.A. and M.K., methodology, G.C., F.F., B.T., L.A. and M.K.; investigation, G.C., F.F., M.M., B.T., S.S., L.A. and M.K.; data curation, G.C., F.F., M.M., S.S., B.T., L.A., A.F. and M.K.; writing-original draft preparation, G.C., F.F., A.F. and M.K.; writing-review and editing, G.C., F.F., M.M., S.S., B.T., L.A., A.F. and M.K.; supervision, F.F., A.F. and M.K.; funding acquisition, F.F. and M.K. All authors have read and agreed to the published version of the manuscript.

Funding: The study was supported by the European Community project No 26220220180: Building Research Centre AgroBioTech and by Fondi di Ateneo of Pisa University.

Conflicts of Interest: The authors declare no conflict of interest.

\section{References}

1. Mandal, M.D.; Mandal, S. Honey: Its medicinal property and antibacterial activity. Asian Pac. J. Trop. Biomed. 2011, 1, 154-160. [CrossRef]

2. Szweda, P. Antimicrobial Activity of Honey. In Honey Analysis; IntechOpen: London, UK, 2017.

3. Fratini, F.; Cilia, G.; Turchi, B.; Felicioli, A. Beeswax: A minireview of its antimicrobial activity and its application in medicine. Asian Pac. J. Trop. Med. 2016, 9, 839-843. [CrossRef] [PubMed]

4. Fratini, F.; Cilia, G.; Turchi, B.; Felicioli, A. Insects, arachnids and centipedes venom: A powerful weapon against bacteria. A literature review. Toxicon 2017, 130, 91-103. [CrossRef] [PubMed]

5. Fratini, F.; Cilia, G.; Mancini, S.; Felicioli, A. Royal Jelly: An ancient remedy with remarkable antibacterial properties. Microbiol. Res. 2016, 192, 130-141. [CrossRef]

6. Felicioli, A.; Cilia, G.; Mancini, S.; Turchi, B.; Galaverna, G.; Cirlini, M.; Cerri, D.; Fratini, F. In vitro antibacterial activity and volatile characterisation of organic Apis mellifera ligustica (Spinola, 1906) beeswax ethanol extracts. Food Biosci. 2019, 29, 102-109. [CrossRef]

7. Libonatti, C.; Varela, S.; Basualdo, M. Antibacterial activity of honey: A review of honey around the world. J. Microbiol. Antimicrob. 2014, 6, 51-56. [CrossRef]

8. Sagona, S.; Bozzicolonna, R.; Nuvoloni, R.; Cilia, G.; Torracca, B.; Felicioli, A. Water activity of fresh bee pollen and mixtures of bee pollen-honey of different botanical origin. LWT 2017, 84, 595-600. [CrossRef]

9. Bucekova, M.; Jardekova, L.; Juricova, V.; Bugarova, V.; Di Marco, G.; Gismondi, A.; Leonardi, D.; Farkasovska, J.; Godocikova, J.; Laho, M.; et al. Antibacterial Activity of Different Blossom Honeys: New Findings. Molecules 2019, 24, 1573. [CrossRef]

10. Bucekova, M.; Buriova, M.; Pekarik, L.; Majtan, V.; Majtan, J. Phytochemicals-mediated production of hydrogen peroxide is crucial for high antibacterial activity of honeydew honey. Sci. Rep. 2018, 8, 1-9. [CrossRef]

11. Grecka, K.; Kuś, P.; Worobo, R.W.; Szweda, P. Study of the Anti-Staphylococcal Potential of Honeys Produced in Northern Poland. Molecules 2018, 23, 260. [CrossRef]

12. Pittia, P.; Antonello, P. Safety by Control of Water Activity: Drying, Smoking, and Salt or Sugar Addition. In Regulating Safety of Traditional and Ethnic Foods; Elsevier BV: Amsterdam, The Netherlands, 2016; pp. 7-28.

13. Zamora, M.C.; Chirife, J.; Roldán, D. On the nature of the relationship between water activity and \% moisture in honey. Food Control. 2006, 17, 642-647. [CrossRef]

14. Ghramh, H.A.; Khan, K.A.; AlShehri, A.M.A. Antibacterial potential of some Saudi honeys from Asir region against selected pathogenic bacteria. Saudi J. Biol. Sci. 2018, 26, 1278-1284. [CrossRef] [PubMed] 
15. Almasaudi, S.B.; Al-Nahari, A.A.; El-Ghany, E.S.M.A.; Barbour, E.; Al Muhayawi, S.M.; Al-Jaouni, S.; Azhar, E.; Qari, M.; Qari, Y.A.; Harakeh, S. Antimicrobial effect of different types of honey on Staphylococcus aureus. Saudi J. Biol. Sci. 2017, 24, 1255-1261. [CrossRef] [PubMed]

16. Al-Nahari, A.A.; Almasaudi, S.B.; El-Ghany, E.S.M.A.; Barbour, E.; Al Jaouni, S.K.; Harakeh, S. Antimicrobial activities of Saudi honey against Pseudomonas aeruginosa. Saudi J. Biol. Sci. 2015, 22, 521-525. [CrossRef] [PubMed]

17. Mohammed, S.E.A.; Kabbashi, A.S.; Koko, W.S.; Rana, R.M.; Adgaba, N.; Ghamdi, A.A. In vitro activity of some natural honeys against Entamoeba histolytica and Giardia lamblia trophozoites. Saudi J. Biol. Sci. 2017, 26, 238-243. [CrossRef]

18. Kacániová, M.; Vukovic, N.; Chlebo, R.; Hascík, P.; Rovná, K.; Cubon, J.; Dzugan, M.; Pasternakiewicz, A. The antimicrobial activity of honey, bee pollen loads and beeswax from Slovakia. Arch. Biol. Sci. 2012, 64, 927-934. [CrossRef]

19. Sagona, S.; Turchi, B.; Fratini, F.; Giusti, M.; Torracca, B.; Biondi, C.; Roberta, N.; Cerri, D.; Felicioli, A. Antimicrobial activity of fifteen Italian honeys against Paenibacillus larvae ATCC 9545. J. Hell. Vet. Med. Soc. 2018, 68, 547-556. [CrossRef]

20. Adetuyi, F.; Ibrahim, T.; Ojei, J.; Ogundahunsi, G. Total phenol, tocopherol and antibacterial quality of honey Apis mellifera sold in Owo community, Ondo State, Nigeria. Afr. J. Biotechnol. 2002, 8, 1305-1309.

21. Louveaux, J.; Maurizio, A.; Vorwohl, G. Methods of Melissopalynology. Bee World 1978, 59, $139-157$. [CrossRef]

22. Horwitz, W.; Latimer, G.W.J. (Eds.) AOAC International Official Methods of Analysis, 18th ed.; AOAC Intl.: Rockville, MD, USA, 2005.

23. Bogdanov, S.; Martin, P.; Lüllmann, C. Harmonised methods of the European Honey Commission. Apidologie 1997, 28, 1-59.

24. Fratini, F.; Mancini, S.; Turchi, B.; Friscia, E.; Pistelli, L.; Giusti, G.; Cerri, D. A novel interpretation of the Fractional Inhibitory Concentration Index: The case Origanum vulgare L. and Leptospermum scoparium J. R. et G. Forst essential oils against Staphylococcus aureus strains. Microbiol. Res. 2017, 195, 11-17. [CrossRef] [PubMed]

25. Oddo, L.P.; Piro, R.; Bruneau, É.; Guyot-Declerck, C.; Ivanov, T.; Piskulová, J.; Flamini, C.; Lheritier, J.; Morlot, M.; Russmann, H.; et al. Main European unifloral honeys: Descriptive sheets. Apidologie 2004, 35, S38-S81. [CrossRef]

26. Taormina, P.J.; Niemira, B.A.; Beuchat, L. Inhibitory activity of honey against foodborne pathogens as influenced by the presence of hydrogen peroxide and level of antioxidant power. Int. J. Food Microbiol. 2001, 69, 217-225. [CrossRef]

27. Basualdo, C.; Sgroy, V.; Finola, M.S.; Marioli, J.M. Comparison of the antibacterial activity of honey from different provenance against bacteria usually isolated from skin wounds. Vet. Microbiol. 2007, 124, 375-381. [CrossRef] [PubMed]

28. Sherlock, O.; Dolan, A.; Athman, R.; Power, A.; Gethin, G.; Cowman, S.; Humphreys, H. Comparison of the antimicrobial activity of Ulmo honey from Chile and Manuka honey against methicillin-resistant Staphylococcus aureus, Escherichia coli and Pseudomonas aeruginosa. BMC Complement. Altern. Med. 2010, 10, 47. [CrossRef] [PubMed]

29. Al-Waili, N.S.; Salom, K.; Butler, G.; Al Ghamdi, A.A. Honey and Microbial Infections: A Review Supporting the Use of Honey for Microbial Control. J. Med. Food 2011, 14, 1079-1096. [CrossRef] [PubMed]

30. Kwakman, P.H.S.; Zaat, S. Antibacterial components of honey. IUBMB Life 2012, 64, 48-55. [CrossRef]

31. Brudzynski, K. Effect of hydrogen peroxide on antibacterial activities of Canadian honeys. Can. J. Microbiol. 2006, 52, 1228-1237. [CrossRef]

32. De-Melo, A.A.M.; De Almeida-Muradian, L.B.; Sancho, M.T.; Pascual-Maté, A. Composition and properties of Apis mellifera honey: A review. J. Apic. Res. 2018, 57, 5-37. [CrossRef]

33. Sagona, S.; Turchi, B.; Fratini, F.; Giusti, M.; Torracca, B.; Nuvoloni, R.; Cerri, D.; Felicioli, A. Preliminary evaluation of glucose oxidase and its products in vitro antimicrobial activities on Paenibacillus larvae ATCC9545 vegetative form. Bull. Insectol. 2015, 68, 233-237.

34. Brudzynski, K.; Sjaarda, C. Antibacterial Compounds of Canadian Honeys Target Bacterial Cell Wall Inducing Phenotype Changes, Growth Inhibition and Cell Lysis That Resemble Action of $\beta$-Lactam Antibiotics. PLoS ONE 2014, 9, e106967. [CrossRef] [PubMed] 
35. Moore, A.R.; Smith, L.A.; Campbell, F.; Seers, K.; McQuay, H.; Moore, A.R. Systematic review of the use of honey as a wound dressing. BMC Complement. Altern. Med. 2001, 1, 2. [CrossRef] [PubMed]

36. George, N.M.; Cutting, K.F. Antibacterial Honey (MedihoneyTM): In-vitro Activity against Clinical Isolates of MRSA, VRE, and Other Multiresistant Gram-negative Organisms Including Pseudomonas aeruginosa. Wounds a Compend. Clin. Res. Pract. 2007, 19, 231-236.

37. Oryan, A.; Alemzadeh, E.; Moshiri, A. Biological properties and therapeutic activities of honey in wound healing: A narrative review and meta-analysis. J. Tissue Viability 2016, 25, 98-118. [CrossRef]

38. Yuksel, P. Comparison of the VersaTrek and BACTEC MGIT 960 systems for the contamination rate, time of detection and recovery of mycobacteria from clinical specimens. Afr. J. Microbiol. Res. 2011, 5, 844-852. [CrossRef]

39. Sakihama, Y.; Cohen, M.F.; Grace, S.C.; Yamasaki, H. Plant phenolic antioxidant and prooxidant activities: Phenolics-induced oxidative damage mediated by metals in plants. Toxicology 2002, 177, 67-80. [CrossRef]

40. Zainol, M.I.; Yusoff, K.M.; Yusof, M.Y. Antibacterial activity of selected Malaysian honey. BMC Complement. Altern. Med. 2013, 13, 129. [CrossRef]

41. Hegazi, A.G.; Al Guthami, F.M.; Al Gethami, A.; Allah, F.M.A.; Saleh, A.A.; Fouad, E. Potential antibacterial activity of some Saudi Arabia honey. Vet. World 2017, 10, 233-237. [CrossRef]

42. Jantakee, K.; Tragoolpua, Y. Activities of different types of Thai honey on pathogenic bacteria causing skin diseases, tyrosinase enzyme and generating free radicals. Biol. Res. 2015, 48, 4. [CrossRef]

43. El-Toum, S.K.; Yagoub, S.O. Compression Study of Anti-microbial Activity of Honey-bees. Res. J. Microbiol. 2007, 2, 776-781. [CrossRef]

44. Chang, X.; Wang, J.; Yang, S.; Chen, S.; Song, Y. Antioxidative, antibrowning and antibacterial activities of sixteen floral honeys. Food Funct. 2011, 2, 541-546. [CrossRef] [PubMed]

45. Vica, M.L.; Glevitzky, M.; Dumitrel, G.-A.; Junie, L.M.; Popa, M. Antibacterial activity of different natural honeys from Transylvania, Romania. J. Environ. Sci. Health Part B 2013, 49, 176-181. [CrossRef] [PubMed]

46. Shamala, T.R.; Jyothi, Y.P.S.; Saibaba, P. Antibacterial effect of honey on the in vitro and in vivo growth of Escherichia coli. World J. Microbiol. Biotechnol. 2002, 18, 863-865. [CrossRef]

47. Badawy, O.; Shafii, S.; Tharwat, E.; Kamal, A. Antibacterial activity of bee honey and its therapeutic usefulness against Escherichia coli 0157:H7 and Salmonella typhimurium infection. Rev. Sci. Tech. 2004, 23, 1011-1022. [CrossRef] [PubMed]

48. Wilkinson, J.; Cavanagh, H.M. Antibacterial Activity of 13 Honeys against Escherichia coli and Pseudomonas aeruginosa. J. Med. Food 2005, 8, 100-103. [CrossRef] [PubMed]

49. Al-Hasani, H.M.H. Study Antibacterial Activity of Honey against Some Common Species of Pathogenic Bacteria. Iraqi J. Sci. 2018, 59, 30-37.

50. Rahman, M.M.; Richardson, A.; Sofian-Azirun, M. Antibacterial activity of propolis and honey against Staphylococcus aureus and Escherichia coli. Afr. J. Microbiol. Res. 2010, 4, 1872-1878.

51. Voidarou, C.; Alexopoulos, A.; Plessas, S.; Karapanou, A.; Mantzourani, I.; Stavropoulou, E.; Fotou, K.; Tzora, A.; Skoufos, I.; Bezirtzoglou, E. Antibacterial activity of different honeys against pathogenic bacteria. Anaerobe 2011, 17, 375-379. [CrossRef]

52. Fidaleo, M.; Zuorro, A.; Lavecchia, R. Antimicrobial Activity of some Italian Honeys against Pathogenic Bacteria. Chem. Eng. Trans. 2011, 24, 1015-1020. [CrossRef]

53. Chauhan, A.; Chauhan, A.; Pandey, V.; Chacko, K.M.; Khandal, R.K. Antibacterial Activity of Raw and Processed Honey. Electron. J. Biol. 2010, 5, 58-66.

54. Coniglio, M.; Faro, G.; Giammanco, G.; Pignato, S.; Marranzano, M. Antimicrobial potential of Sicilian honeys against commensal Escherichia coli and pathogenic Salmonella serovar Infantis. J. Prev. Med. Hyg. 2013, 54, 223-226. [PubMed]

55. Stagos, D.; Soulitsiotis, N.; Tsadila, C.; Papaeconomou, S.; Arvanitis, C.; Ntontos, A.; Karkanta, F.; Adamou-Androulaki, S.; Petrotos, K.; Spandidos, D.A.; et al. Antibacterial and antioxidant activity of different types of honey derived from Mount Olympus in Greece. Int. J. Mol. Med. 2018, 42, 726-734. [CrossRef] [PubMed]

56. Baltrušaitytè, V.; Venskutonis, P.R.; Čeksterylè, V. Antibacterial Activity of Honey and Beebread of Different Origin against S. aureus and S. epidermidis. Food Technol. Biotechnol. 2007, 45, 201-208.

57. Dinkov, D. The antibacterial activity of acacia, multifloral and oak honeydew honeys. Int. J. Vet. Sci. Anim. Husb. 2016, 1, 7-10. 
58. Kuś, P.; Szweda, P.; Jerković, I.; Tuberoso, C.I. Activity of Polish unifloral honeys against pathogenic bacteria and its correlation with colour, phenolic content, antioxidant capacity and other parameters. Lett. Appl. Microbiol. 2016, 62, 269-276. [CrossRef] [PubMed]

59. Anthimidou, E.; Mossialos, D. Antibacterial Activity of Greek and Cypriot Honeys against Staphylococcus aureus and Pseudomonas aeruginosa in Comparison to Manuka Honey. J. Med. Food 2013, 16, 42-47. [CrossRef] [PubMed]

60. Szczęsna, T. Protein content and amino acid composition of bee-collected pollen from selected botanical origins. J. Apic. Sci. 2006, 50, 81-90.

61. Roulston, T.H.; Cane, J.H. Pollen nutritional content and digestibility for animals. Plant Syst. Evol. 2000, 222, 187-209. [CrossRef]

62. Nogueira, C.; Iglesias, A.; Feás, X.; Estevinho, L.M. Commercial Bee Pollen with Different Geographical Origins: A Comprehensive Approach. Int. J. Mol. Sci. 2012, 13, 11173-11187. [CrossRef]

63. Denisow, B.; Denisow-Pietrzyk, M. Biological and therapeutic properties of bee pollen: A review. J. Sci. Food Agric. 2016, 96, 4303-4309. [CrossRef]

Publisher's Note: MDPI stays neutral with regard to jurisdictional claims in published maps and institutional affiliations.

(C) 2020 by the authors. Licensee MDPI, Basel, Switzerland. This article is an open access article distributed under the terms and conditions of the Creative Commons Attribution (CC BY) license (http://creativecommons.org/licenses/by/4.0/). 